\title{
The effects of doxorubicin-loaded liposomes on viability, stem cell surface marker expression and secretion of vascular endothelial growth factor of three-dimensional stem cell spheroids
}

\author{
HYUNJIN LEE $^{1 *}$, JIHWAN SON ${ }^{2 *}$, CHAE-BIN NA ${ }^{1}$, GAWON YI ${ }^{2}$, HEEBEOM KOO $^{2}$ and JUN-BEOM PARK ${ }^{1,3}$ \\ Departments of ${ }^{1}$ Periodontics and ${ }^{2}$ Medical Lifescience, College of Medicine, \\ The Catholic University of Korea; ${ }^{3}$ Department of Periodontics, Seoul St Mary's Hospital, \\ College of Medicine, The Catholic University of Korea, Seoul 06591, Republic of Korea
}

Received September 17, 2017; Accepted March 20, 2018

DOI: $10.3892 /$ etm.2018.6064

\begin{abstract}
The aim of the present study was to evaluate the effects of anionic, cationic and neutral liposomes containing doxorubicin on the cellular viability and osteogenic differentiation of three-dimensional stem cell spheroids. Doxorubicin-loaded liposomes were prepared using the traditional thin-lipid-film-hydration method and were characterized using transmission electron microscopy and a zeta potential analyzer. The doxorubicin release profile from these liposomes was also analyzed in vitro. Three-dimensional cell spheroids were fabricated using silicon elastomer-based concave microwells. Qualitative results of cellular viability were observed using a confocal microscope and quantitative cellular viability was evaluated using a Cell-Counting Kit-8 (CCK-8) assay. Furthermore, the secretion of vascular endothelial growth factor was evaluated. Western blot analysis was performed to assess the expression of collagen I and glyceraldehyde 3-phosphate. Results indicated that the spheroids were well formed in silicon elastomer-based concave microwells on day 1. In general, the shapes of the cells in the in the doxorubicin-loaded anionic, cationic and neutral liposome groups were similar to the control group except for the $10 \mu \mathrm{g} / \mathrm{ml}$ groups on days 3,5 , and 7 . No significant changes in cellular viability were noted with the addition of doxorubicin
\end{abstract}

Correspondence to: Professor Jun-Beom Park, Department of Periodontics, College of Medicine, The Catholic University of Korea, 222 Banpo-daero, Seocho-gu, Seoul 06591, Republic of Korea

E-mail: jbassoonis@yahoo.co.kr

Professor Heebeom Koo, Department of Medical Lifescience, College of Medicine, The Catholic University of Korea, 222 Banpo-daero, Seocho-gu, Seoul 06591, Republic of Korea E-mail: hbkoo@catholic.ac.kr

${ }^{*}$ Contributed equally

Key words: bone marrow, cell differentiation, cell proliferation, cellular spheroids, doxorubicin, gingiva, liposomes, stem cells at day 1 but significant decreases in cellular viability were noted with application of doxorubicin at day 5. Notably, higher concentrations of doxorubicin reduced the secretion of vascular endothelial growth factor and stem cell marker expression. To conclude, the present study indicated that doxorubicin-loaded anionic liposomes produced the most sustained release profile and cationic liposomes produced the highest uptake of the stem cell spheroids. These findings suggested that higher concentrations of doxorubicin-loaded liposomes affected cellular viability, the secretion of vascular endothelial growth factor and stem cell marker expression.

\section{Introduction}

Doxorubicin is one of the most widely used anthracycline antibiotic/anticancer agents (1). It is an effective antineoplastic drug, but its usage is limited by various complications, including its cardiotoxicity (2). To solve this problem, doxorubicin-loaded nanoparticles including liposomes were developed and they could result in improved tumor-growth inhibition with less general toxicity compared to the free drug molecules (3). Liposomal formulations of doxorubicin, can achieve locally high drug concentrations within a tumor and tumor vasculature while maintaining low systemic toxicity (4). In previous reports, various liposomes showed sustained release of doxorubicin and produced a reliable cure of local cancer in mouse models (4).

Three-dimensional culture system is more similar to tissue conditions in vivo and can mimic native environments, unlike the two-dimensional culture system (5). Three-dimensional culture models have been proposed due to their various advantages over two-dimensional culture systems (6). Three-dimensional environment has been reported to enhance reprogramming process (7). Three-dimensional spherical spatial boundary conditions have been reported to regulate the differentiation of mesenchymal stem cells (8). Moreover, three-dimensional culture system can be used for the evaluation of intercellular interactions in the regulation of cell proliferation and differentiation $(9,10)$. Doxorubicin is reported to suppress bone marrow stem cells while expanding cancer stem cells (11). However, the effects of doxorubicin-loaded anionic, 
cationic, and neutral liposomes on the stem cell spheroids derived from bone marrow and gingiva has not been tested yet. The aim of this report is to evaluate the effects of anionic, cationic, and neutral liposomes containing doxorubicin on the cellular viability and stem cell surface maker expression of three-dimensional stem cell spheroids. To the authors' knowledge, this is the first report evaluating the effects of anionic, cationic, and neutral liposomes containing doxorubicin on stem cell spheroids consisting of human gingiva-derived stem cells and bone marrow-derived stem cells.

\section{Materials and methods}

Materials. 1,2-Dipalmitoyl-sn-glycero-3-phosphocholine (DPPC) and 1,2-Dipalmitoyl-sn-glycero-3-phosphoserine, sodium salt (DPPS) were purchased from Echelon Biosciences (Salt Lake City, UT, USA). 1,2-dipalmitoyl-3-trimethylammonium-propane [chloride salt (16:0 TAP)] was purchased from Avanti Polar Lipids (Birmingham, AL, USA). Cholesterol was purchased from Sigma-Aldrich (Merck KGaA, Darmstadt, Germany). Dichloromethane was purchased from Daejung Chemical (Cheongwon, Korea). A dialysis membrane [pre-wetted RC Tubing (MWCO: 25 kD)] was purchased from Spectrum (Spectra/Por; Laguna Hills, CA, USA). Dimethyl sulfoxide, $99.0 \%$ (methyl sulfoxide, DMSO) and Triton X-100 were purchased from Samchun Pure Chemical (Pyeongtaek, Korea). Phosphate-buffered saline (PBS, pH 7.4) was purchased from Gibco (Thermo Fisher Scientific, Inc., Waltham, MA, USA). Doxorubicin hydrochloride was purchased from LC laboratories (Woburn, MA, USA).

\section{Methods}

Preparation of doxorubicin-loaded liposomes. Liposomes were prepared by the thin-lipid-film-hydration method from the mixture. For the neutral liposome, cationic liposome, and anionic liposome, we used DPPC:Cholesterol=10:1; DPPC: 16:0TAP:Cholesterol=5:5:1; DPPC:DPPS:Cholesterol=5:5:1 (weight ratio), respectively. Briefly, the lipids were dissolved in dichloromethane and the solvent was removed via evaporation under a reduced pressure at $55^{\circ} \mathrm{C}$. Then, a thin film of lipids was dispersed in distilled water (lipid concentration was $2.2 \mathrm{mg} / \mathrm{ml}$ ) with doxorubicin hydrochloride by sonication. Finally, unloaded doxorubicin was removed through dialysis, using distilled water for $1 \mathrm{~h}$. The amount of doxorubicin in liposomes was evaluated based on the fluorescence of doxorubicin (490/570 nm) after the complete disruption of liposomes by Triton X-100.

Size and morphology of liposomes. The average size diameter, polydispersity, and zeta potentials of the liposomes were determined using a Zetasizer Nano ZS90 (Malvern Instruments, Malvern, UK) and Data Transfer Assistance (DTA) software at $25^{\circ} \mathrm{C}$. Zeta potential was measured in PBS. The morphology of liposomes was observed by transmission electron microscopy using negative staining with $2 \%(\mathrm{w} / \mathrm{v})$ uranyl acetate solution for $10 \mathrm{~min}$.

Doxorubicin release from liposomes. The release of doxorubicin from liposomes was evaluated over time at room temperature in PBS. Doxorubicin-loaded liposomes were put in a dialysis bag and the amount of remaining doxorubicin in the bag was measured using points based on fluorescence as time went on.

Formation of cell spheroids with human gingiva-derived stem cells and bone marrow-derived stem cells. Stem cell spheroids were formed in the silicon elastomer-based concave microwells (H389600, StemFIT 3D; MicroFIT, Seongnam, Korea) with $600 \mu \mathrm{m}$ diameters. Gingiva-derived stem cells and bone marrow-derived stem cells in the amount of $9 \times 10^{5}$ were seeded and subsequently cultured to investigate cellular behavior. Human bone marrow-derived mesenchymal stem cells (Catholic MASTER Cells) were obtained from Catholic Institute of Cell Therapy (CIC; Seoul, Korea). The Institutional Review Board of Seoul St Mary's Hospital, College of Medicine, Catholic University of Korea (Seoul, Korea), approved this study (KC17SESI0290 and KC11SISI0348), and informed consents from the study participants were obtained. All the methods used in this study were performed in accordance with the relevant guidelines and regulations. Gingival tissues were collected from the patient (64-year-old female) visiting the Department of Periodontics, Seoul St Mary's Hospital, on July 2013. In short, gingivae were de-epithelialized, minced, and digested in an $\alpha$-modified minimal essential medium ( $\alpha$-MEM; Gibco; Thermo Fisher Scientific, Inc.) containing collagenase IV (2 mg/ml; Sigma-Aldrich; Merck KGaA) and dispase (1 mg/ml; Sigma-Aldrich; Merck KGaA). The ratios between human gingiva-derived stem cells and human bone marrow-derived mesenchymal stem cells were $2: 1$. Cell aggregation and cell-spheroid formation were observed under an inverted microscope (Leica DM IRM; Leica Microsystems, Wetzlar, Germany), and the images were saved as JPGs. The groups consisted of i) unloaded control group; ii) doxorubicin, $1 \mu \mathrm{g} / \mathrm{ml}$ (D1); iii) doxorubicin, $10 \mu \mathrm{g} / \mathrm{ml}$ (D10); iv) unloaded anionic group (A0); v) anionic group loaded with doxorubicin at $1 \mu \mathrm{g} / \mathrm{ml}$ (A1); vi) anionic group loaded with doxorubicin at $10 \mu \mathrm{g} / \mathrm{ml}$ (A10); vii) unloaded cationic group (C0); viii) cationic group loaded with doxorubicin at $1 \mu \mathrm{g} / \mathrm{ml}(\mathrm{C} 1)$; ix) cationic loaded with doxorubicin at $10 \mu \mathrm{g} / \mathrm{ml}$ (C10); x) unloaded neutral (N0); xi) neutral group loaded with doxorubicin at $1 \mu \mathrm{g} / \mathrm{ml}(\mathrm{N} 1)$; and xii) neutral group loaded with doxorubicin at $10 \mu \mathrm{g} / \mathrm{ml}(\mathrm{N} 10)$.

Determination of cell viability. The viability of spheroids was qualitatively analyzed with the Live/Dead kit assay (Molecular Probes, Eugene, OR, USA). The assay is based on the principle that the activity of intracellular esterase causes non-fluorescent, cell-permeant calcein acetoxymethyl ester to become intensely fluorescent, giving the viable spheroids an intense, uniform, green fluorescence. The ethidium homodimer enters into the damaged cell membrane and then binds to nucleic acids, thereby producing a red fluorescence in the dead cells.

Stem cell spheroids were cultured in an $\alpha$-MEM (Gibco; Thermo Fisher Scientific, Inc.) containing 15\% fetal bovine serum (Gibco; Thermo Fisher Scientific, Inc.), $100 \mathrm{U} / \mathrm{ml}$ of penicillin, and $100 \mu \mathrm{g} / \mathrm{ml}$ of streptomycin (Sigma-Aldrich; Merck KGaA), 200 mM of L-Glutamine (Sigma-Aldrich; Merck $\mathrm{KGaA}$ ), and $10 \mathrm{mM}$ of ascorbic acid 2-phosphate (Sigma-Aldrich; Merck KGaA). These spheroids were washed twice with the growth media, followed by suspension in $1 \mathrm{ml}$ of $\alpha$-MEM containing $2 \mu \mathrm{l}$ of $50 \mathrm{mM}$ calcein acetoxymethyl ester 
working solution and $4 \mu \mathrm{l}$ of the $2 \mathrm{mM}$ ethidium homodimer- 1 for $30 \mathrm{~min}$ at room temperature. The spheroids stained with calcein acetoxymethyl ester and ethidium homodimer-1 were observed under a fluorescence microscope (Axiovert 200; Carl Zeiss AG, Oberkochen, Germany) at days 1, 3 and 5.

A cell-viability analysis was performed on days $1,3,5$, and 7. WST-8 [2-(2-methoxy-4-nitrophenyl)-3-(4-nitrophen yl)-5-(2,4-disulfophenyl)-2H tetrazolium, monosodium salt] [Cell-Counting Kit-8 (CCK-8); Dojindo, Tokyo, Japan] was added to the cultures, and the spheres were incubated for $1 \mathrm{~h}$ at $37^{\circ} \mathrm{C}$. Viable cells were identified by the assay, which relies on the ability of mitochondrial dehydrogenases to oxidize WST-8 into a formazan product. The spectrophotometric absorbance of the samples was measured at $450 \mathrm{~nm}$ using a microplate reader (BioTek Instruments, Inc., Winooski, VT, USA).

Paracrine effect evaluation of the secretion of human vascular endothelial growth factor. The determination of human vascular endothelial growth factor from three-dimensional systems was performed using a commercially available kit (Quantikine ${ }^{\circledR}$ ELISA, cat. no. DVE00; R\&D Systems, Inc., Minneapolis, MN, USA). All reagents and samples were prepared according to the manufacturer's recommendations. The absorbance levels at 540 and $570 \mathrm{~nm}$ were measured and the differences were used as the value.

Maintenance of stemness. After cultivation for 7 days, the spheroids were retrieved. Antibodies were purchased from R\&D Systems and then diluted to a 50X concentration. Human SSEA-4 (Clone MC-813-70; SC023) conjugated to NHL493 (green) and human TRA-1-60(R) (Clone TRA-1-60; SC023) conjugated to NL557 (red) were used as positive markers of human stem cells. After spheres were incubated for $1 \mathrm{~h}$ at $37^{\circ} \mathrm{C}$, the antibody-containing media were removed, and the cells were rinsed with fresh media and re-fed with fresh media. The spheroids were visualized under a fluorescence microscope (Axiovert 200; Carl Zeiss AG).

Western blot analysis. Stem cells were washed two times with ice-cold PBS and solubilized in lysis buffer on day 7 for $30 \mathrm{~min}$. The lysates were centrifuged at $15,000 \mathrm{x} \mathrm{g}$ for $10 \mathrm{~min}$ at $4^{\circ} \mathrm{C}$. These samples were then separated by sodium dodecyl sulfate polyacrylamide gel electrophoresis (Mini-PROTEAN ${ }^{\circledR}$ TGX $^{\text {тм }}$ Precast Gels; Bio-Rad Laboratories, Inc., Hercules, CA, USA), transferred to polyvinylidene difluoride membranes (Immun-Blot ${ }^{\circledR}$; Bio-Rad Laboratories, Inc.) and immunoblotted with the corresponding antibodies and enhanced chemiluminescent detection kits. Primary antibodies against collagen I (ab6308) and glyceraldehyde 3-phosphate (GAPDH; ab9485) and secondary antibodies were purchased from Enzo Life Sciences, Inc. (Farmingdale, NY, USA), Cell Signaling Technology, Inc. (Danvers, MA, USA), Thermo Fisher Scientific, Inc., and Santa Cruz Biotechnology, Inc. (Santa Cruz, CA, USA). A quantitative analysis of the protein expressions of Collagen I and GAPDH was conducted with image processing and analyzing software (ImageJ; National Institutes of Health, Bethesda, MD, USA).

Statistical analysis. The data are represented as means \pm standard deviations of the experiments. A test of normality was performed with Shapiro-Wilk test, and a two-way analysis of variance (ANOVA) with a post hoc Tukey test was performed to determine the differences between the groups using a commercially available program (SPSS 12 for Windows; SPSS Inc., Chicago, IL, USA). $\mathrm{P}<0.05$ was considered to indicate a statistically significant difference.

\section{Results}

Characterization of doxorubicin-loaded liposomes. Fig. 1 shows the transmission electron microscopy of anionic, cationic, and neutral liposomes by film-hydration methods and doxorubicin loaded inside of the liposomes. The sizes of fabricated liposomes were approximately 100 to $200 \mathrm{~nm}$, and they have spherical shapes in aqueous condition (Fig. 1). Size distribution of liposomes is shown in Table I. The zeta potential values were $-41.9,+24.4$, and +0.176 , for anionic, cationic, and neutral liposomes showing the surface charges were properly controlled based on lipid composition. During the in vitro release test, doxorubicin was gradually released from liposomes (Fig. 1D). The release rate was slowest in the case of anionic liposomes compared to the other two samples.

Evaluation of cell morphology and cellular viability. Spheroids were well formed in silicon elastomer-based concave microwells on day 1 (Fig. 2A). There were no significant changes in the morphology with the application of doxorubicin on day 1 . The results of morphology of days 3,5 , and 7 are shown in Fig. 2B-D, respectively. In general, the shapes of the cells in the tested groups were similar to the control group, except for the $10 \mu \mathrm{g} / \mathrm{ml}$ group. Noticeable changes in the morphology were noted for D10 and C10 at day 3 (Fig. 2B). The shapes of the cells in these groups were larger, and cells were adrift. There were no significant changes in the morphology with the longer incubation time (Fig. 2C and D). The diameters of the spheroids for D0, D1, D10, A0, A1, A10, C0, C1, C10, N0, and N1 on day 1 were shown in Fig. 2E. The diameters of the spheroids were maintained throughout the incubation time but had a tendency of decrease in size $(\mathrm{P}<0.05)$.

The cellular viability was determined via live and dead assay using confocal microscope as shown in Fig. 3. In the result of day 1, most of the cells in the spheroids emitted green fluorescence and the morphology of the spheriods was round (Fig. 3). The increase of red fluorescence was noted with higher doses of doxorubicin. The quantitative results for D0, D1, D10, $\mathrm{A} 0, \mathrm{~A} 1, \mathrm{~A} 10, \mathrm{C} 0, \mathrm{C} 1, \mathrm{C} 10, \mathrm{~N} 0$, and $\mathrm{N} 1$ on day 1 were shown in Fig. 3E. The results of day 3 and day 5 are shown in Figs. 4 and 5, respectively. The quantitative results for D0, D1, D10, $\mathrm{A} 0, \mathrm{~A} 1, \mathrm{~A} 10, \mathrm{C} 0, \mathrm{C} 1, \mathrm{C} 10, \mathrm{~N} 0$, and $\mathrm{N} 1$ on day 3 and day 5 were shown in Figs. 4E and 5E, respectively. The CCK-8 results on days 1,3, 5, and 7 are shown in Fig. 6. No significant changes in cellular viability were noted with the addition of doxorubicin on day 1 . However, significant decreases in cellular viability were noted with the application of doxorubicin on day 5 .

Maintenance of stemness and secretion of human vascular endothelial growth factor from spheroids. Spheroids were stained with NL493-conjugated SSEA-4 (green) antibodies on day 7 (Fig. 7A). The spheroids were positive for the stem cell markers SSEA-4, which suggests that these spheroids 
Table I. Size distribution of liposomes.

\begin{tabular}{lccc}
\hline Liposome & Z-average $(\mathrm{nm})$ & Polydispersity index & Zeta potential $(\mathrm{mV})$ \\
\hline Neutral & 162.1 & 0.159 & +0.176 \\
Cationic & 91.40 & 0.229 & +24.4 \\
Anionic & 186.2 & 0.210 & -41.9 \\
\hline
\end{tabular}
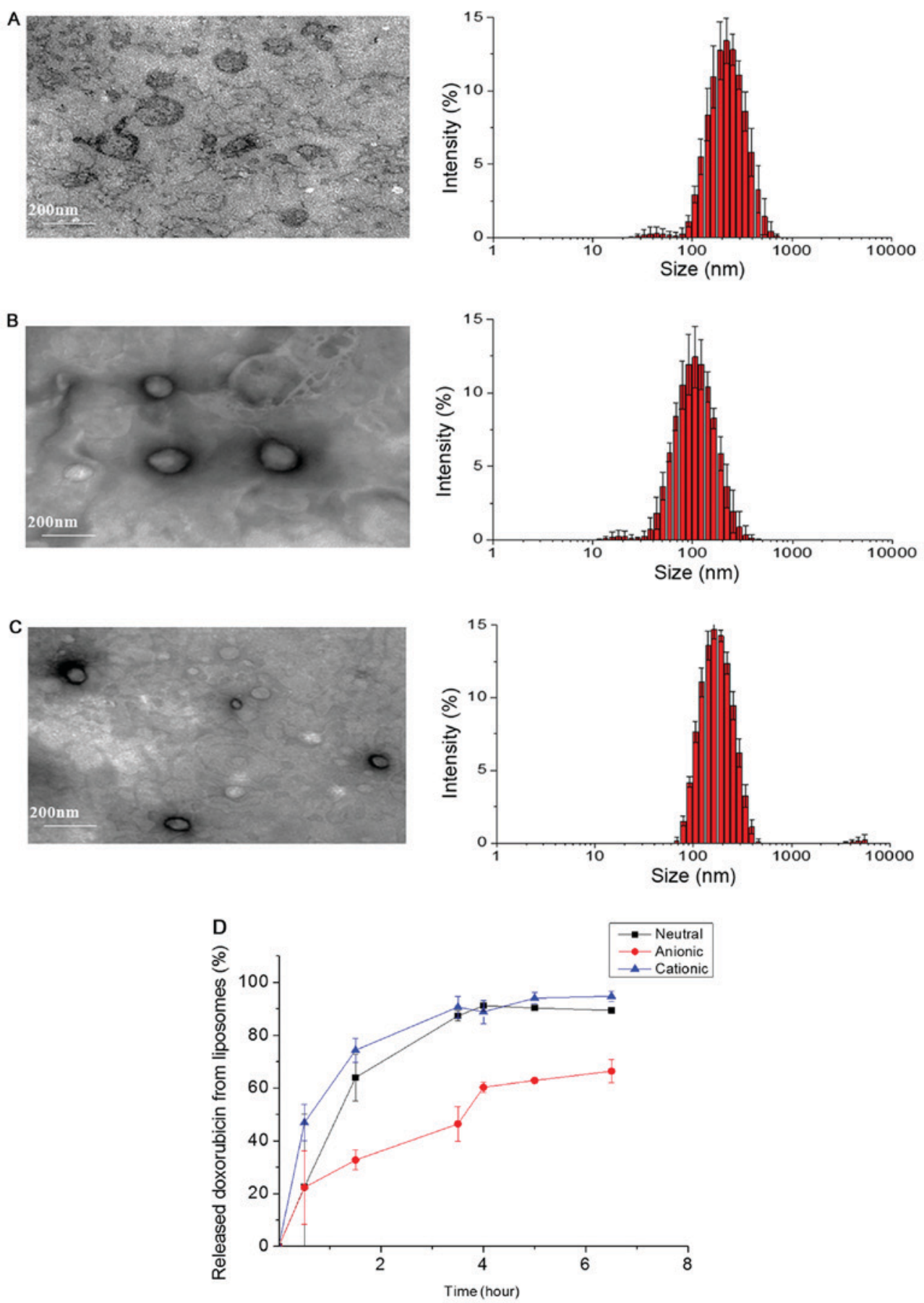

Figure 1. Size distribution and transmission-electron-microscopy images of liposomes. (A) Anionic liposome; (B) cationic liposome; (C) neutral liposome; and (D) in vitro release of doxorubicin from liposomes.

primarily contained undifferentiated human stem cells until the incubation time of 7 days. The secretions of vascular endothelial growth factors from the spheroids were noted in all groups for day 3 and day 7 (Fig. 7B). The results clearly 
A
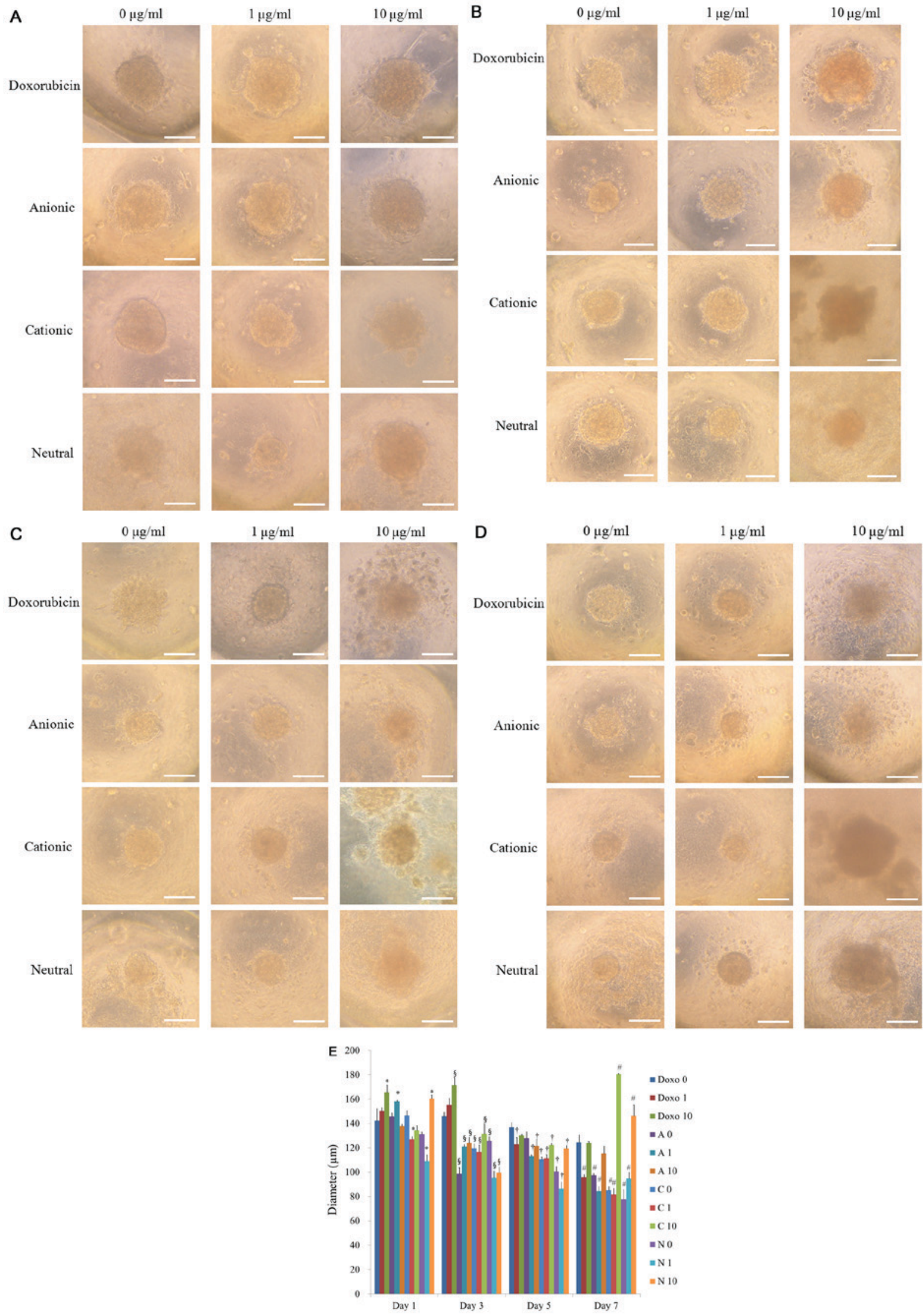

Figure 2. Morphology of cell spheroids cultured in growth media. Morphology of the cell spheroids (A) on day 1, (B) day 3, (C) day 5 and (D) day 7 (original magnification, x200). Scale bar $=100 \mu \mathrm{m}$. (E) Diameter of cell spheroids on days $1,3,5$, and 7 . ${ }^{*} \mathrm{P}<0.05$ vs. Doxo 0 group on day 1 ; ${ }^{\S} \mathrm{P}<0.05$ vs. Doxo 0 group on day 3 ; ${ }^{\dagger} \mathrm{P}<0.05$ vs. Doxo 0 group on day 5 ; and ${ }^{\#} \mathrm{P}<0.05$ vs. Doxo 0 group on day 7 . The groups consisted of unloaded control group (Doxo 0); $1 \mu \mathrm{g} / \mathrm{ml}$ doxorubicin, (Doxo 1); $10 \mu \mathrm{g} / \mathrm{ml}$ doxorubicin, (Doxo 10); unloaded anionic group (A0); anionic group loaded with $1 \mu \mathrm{g} / \mathrm{ml}$ doxorubicin (A1); anionic group loaded with $10 \mu \mathrm{g} / \mathrm{ml}$ doxorubicin (A10); unloaded cationic group (C0); cationic group loaded with $1 \mu \mathrm{g} / \mathrm{ml}$ doxorubicin (C1); cationic loaded with $10 \mu \mathrm{g} / \mathrm{ml}$ doxorubicin (C10); unloaded neutral (N0); neutral group loaded with $1 \mu \mathrm{g} / \mathrm{ml}$ doxorubicin (N1); and neutral group loaded with $10 \mu \mathrm{g} / \mathrm{ml}$ doxorubicin (N10). 
A Live

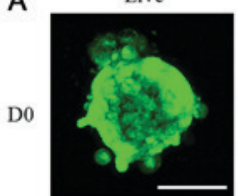

D1
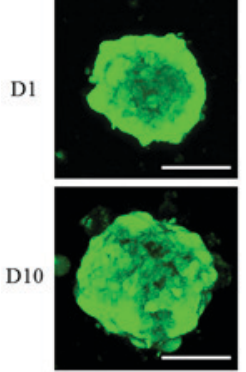

C

$\mathrm{C} 0$
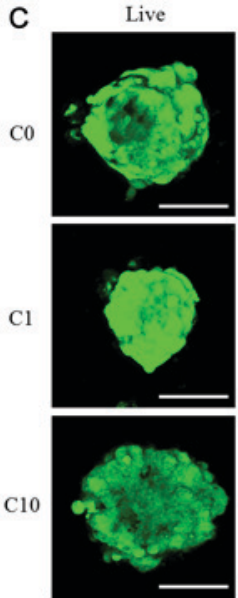

Dead
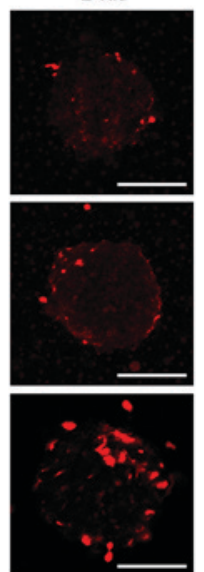

Dead
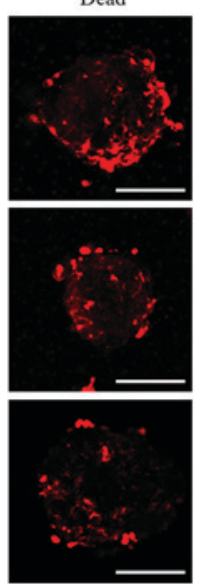

Merged
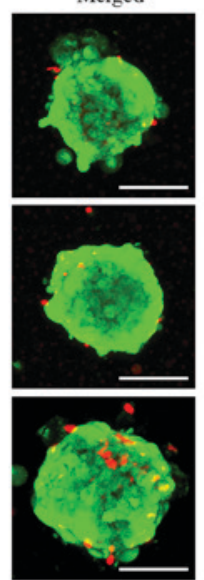

Merged
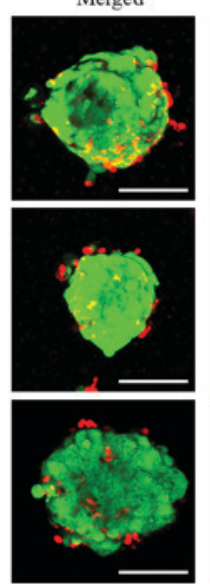

Center
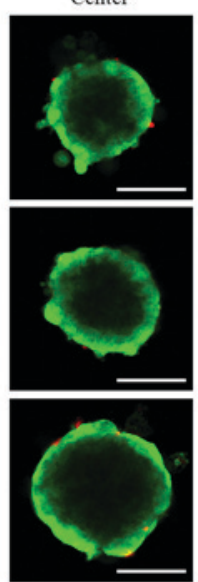

Center
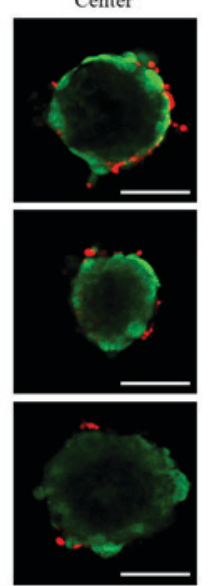

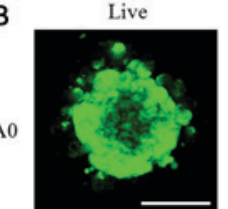

A 1
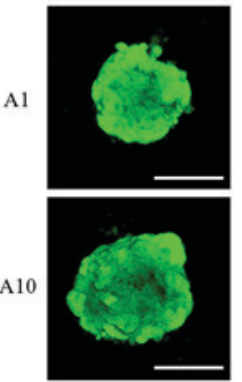

D

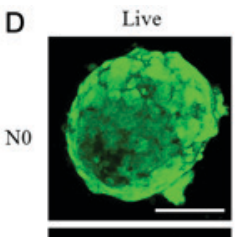

N1
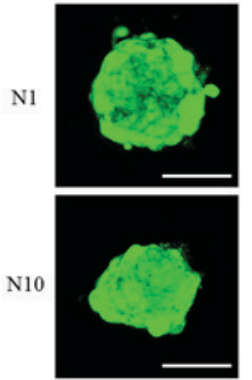

Dead
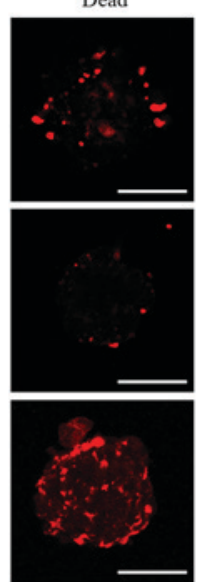

Dead
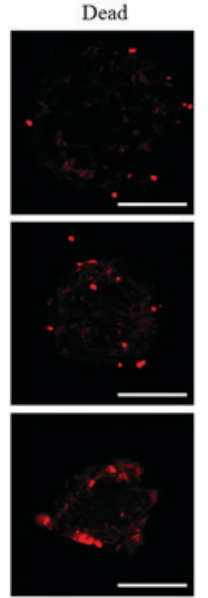

Merged
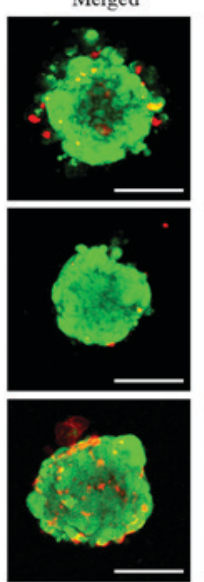

Merged
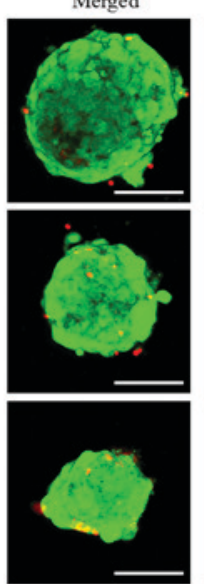

Center
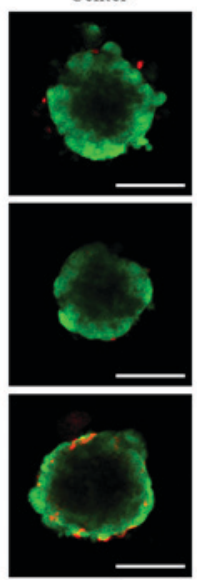

Center
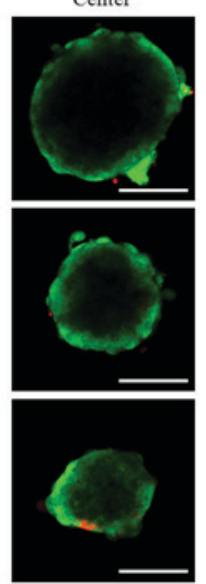

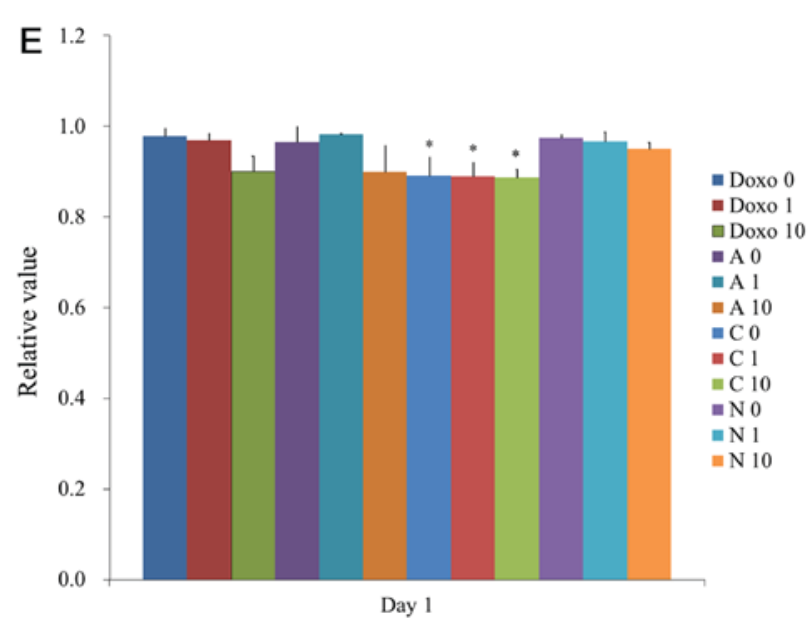

Figure 3. Qualitative results of cellular viability under a confocal microscope on day 1. Live images, dead images, merged images and central images are provided. (A) Doxorubicin group; (B) anionic liposome; (C) cationic liposome; and (D) neutral liposome. Scale bar=100 $\mu \mathrm{m}$ (original magnification, x100). (E) Quantitative results of cellular viability on day 1. $\mathrm{P}<0.05$ vs. Doxo 0 group. The groups consisted of unloaded control group (Doxo 0 ); $1 \mu \mathrm{g} / \mathrm{ml}$ doxorubicin, (Doxo 1); $10 \mu \mathrm{g} / \mathrm{ml}$ doxorubicin, (Doxo 10); unloaded anionic group (A0); anionic group loaded with $1 \mu \mathrm{g} / \mathrm{ml}$ doxorubicin (A1); anionic group loaded with $10 \mu \mathrm{g} / \mathrm{ml}$ doxorubicin (A10); unloaded cationic group (C0); cationic group loaded with $1 \mu \mathrm{g} / \mathrm{ml}$ doxorubicin (C1); cationic loaded with $10 \mu \mathrm{g} / \mathrm{ml}$ doxorubicin (C10); unloaded neutral (N0); neutral group loaded with $1 \mu \mathrm{g} / \mathrm{ml}$ doxorubicin (N1); and neutral group loaded with $10 \mu \mathrm{g} / \mathrm{ml} \mathrm{doxorubicin}$ (N10).

showed that the secretion of the vascular endothelial growth factor was observable on the third and seventh day and a stable secretion of vascular endothelial growth factor during the culture period. More severe decrease of secretions was noted with higher concentrations of doxorubicin. The lowest secretion of vascular endothelial growth factor was seen in C10 group on day 7 .
Western blot. A Western blot analysis was performed to detect the protein expression of collagen I, and GAPDH on day 7 (Fig. 7C). A limited quantity of protein could only be obtained for the D10, A10, C10 and N10 groups, and cells in the N10 group appeared to have reduced viability. There were statistically significant differences were noted in D10, A10, and C10 groups $(\mathrm{P}<0.05)$. Highest expressions were seen in A10 group. 

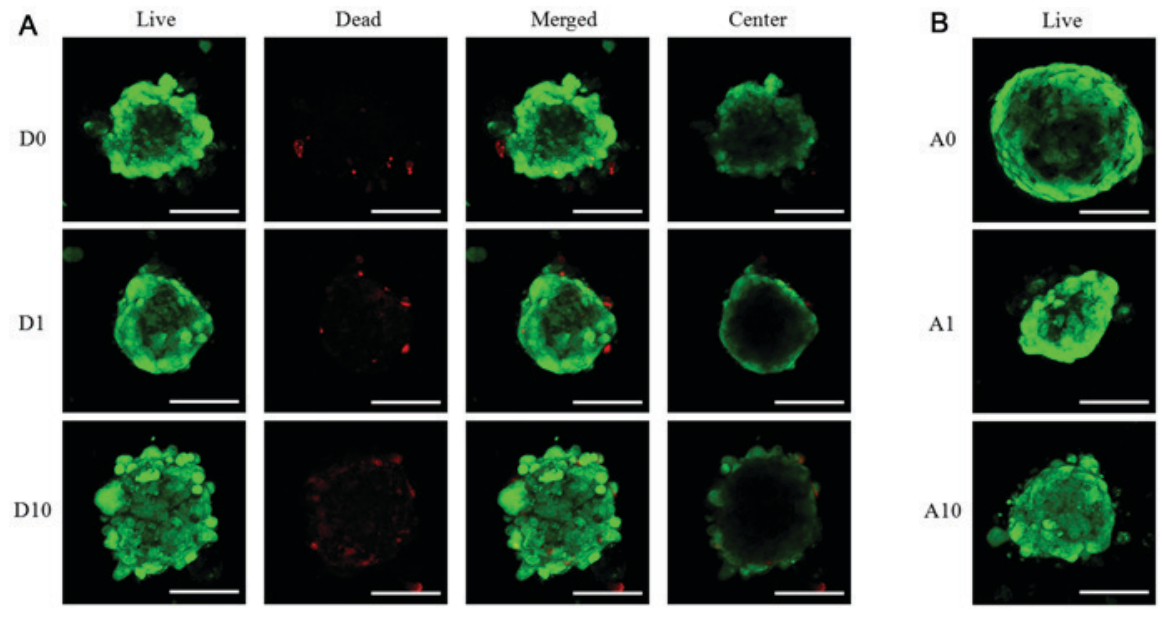

Dead
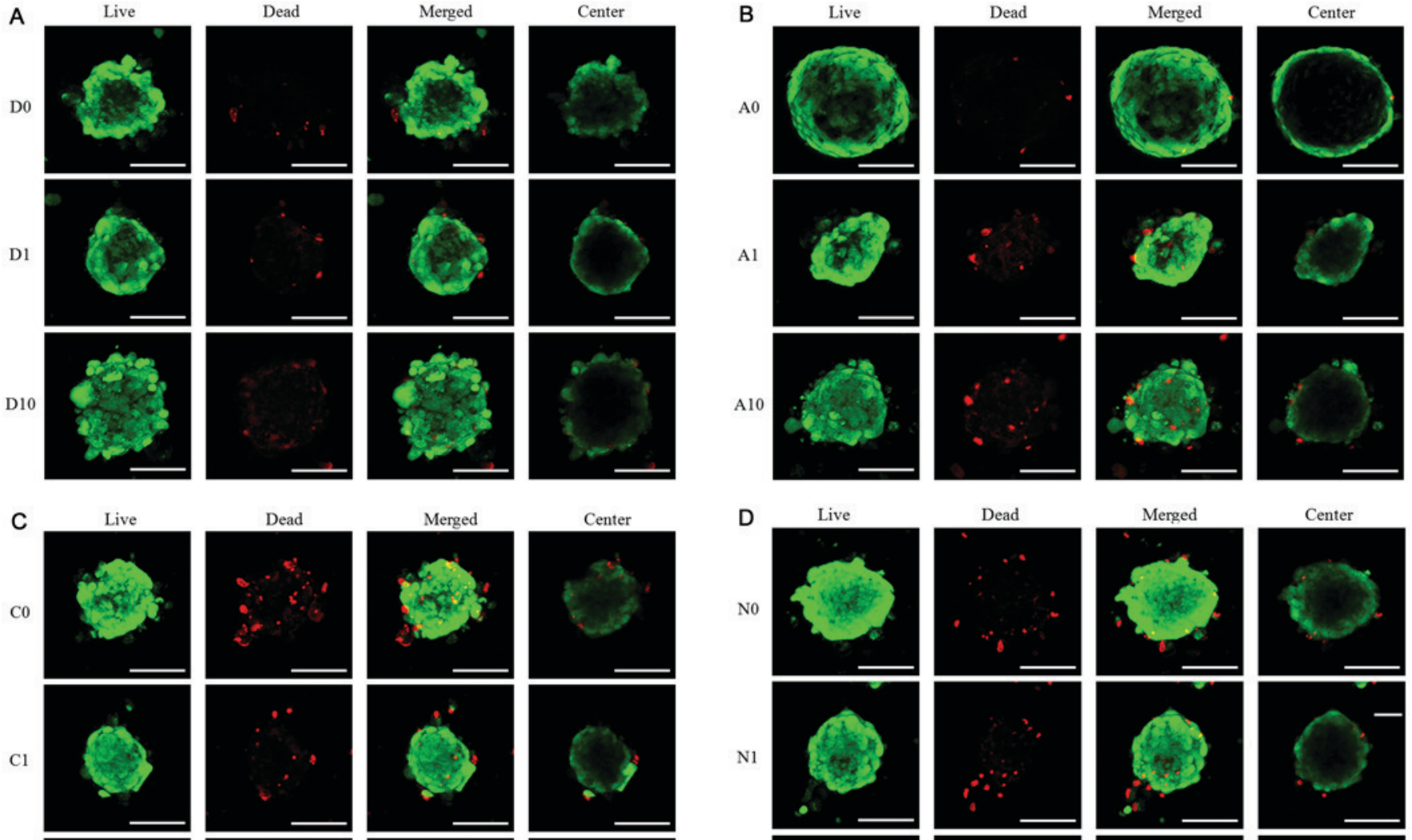

$\mathrm{D}$
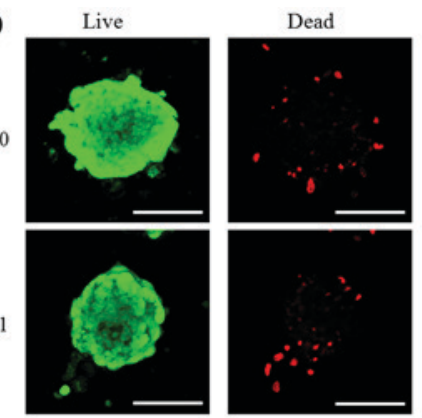

Merged
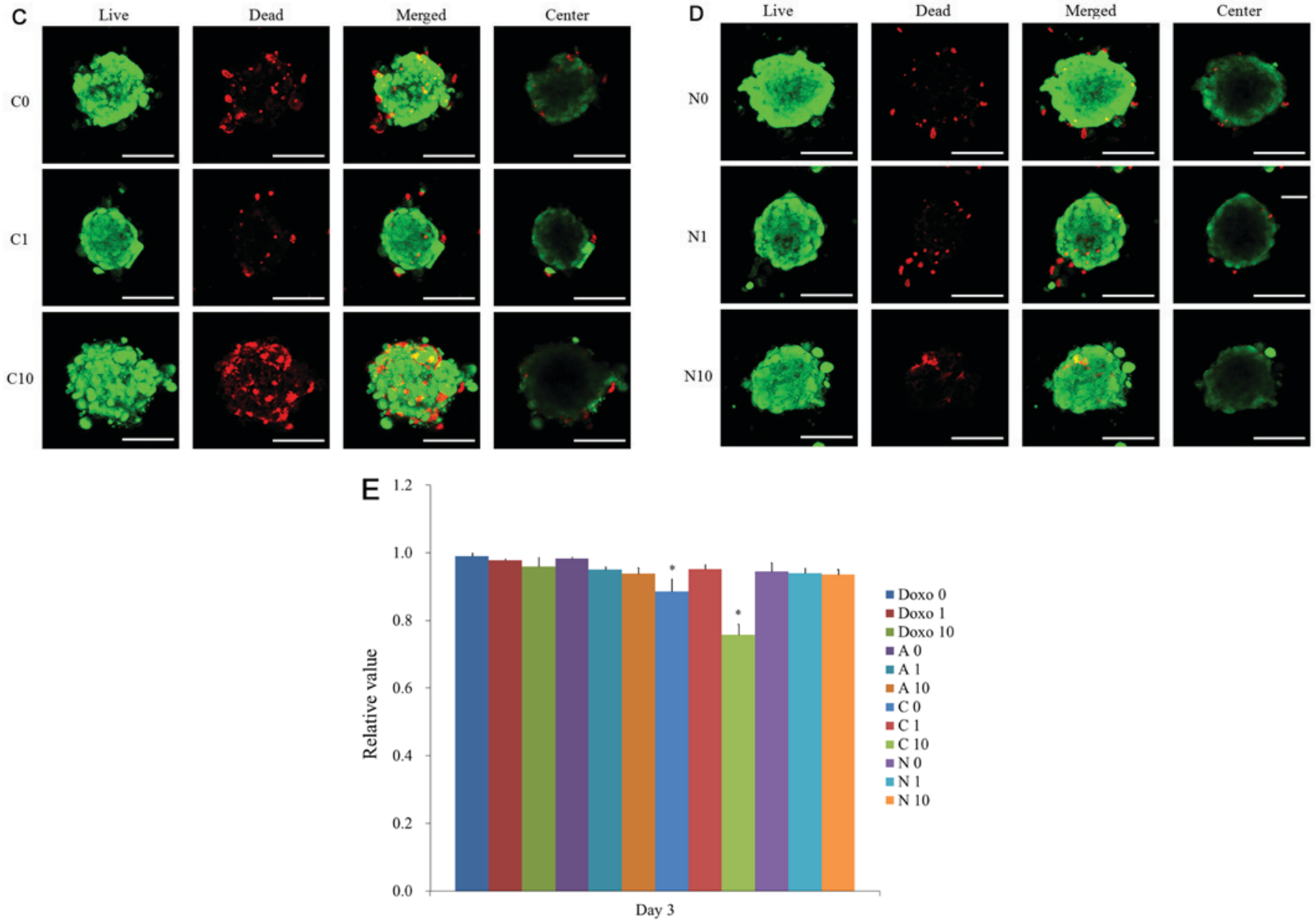

Figure 4. Qualitative results of cellular viability under a confocal microscope on day 3. Live images, dead images, merged images, and central images are provided. (A) Doxorubicin group; (B) anionic liposome; (C) cationic liposome; and (D) neutral liposome. Scale bar=100 $\mu \mathrm{m}$ (original magnification, x100). (E) Quantitative results of cellular viability on day 3. "P<0.05 vs. Doxo 0 group. The groups consisted of unloaded control group (Doxo 0 ); $1 \mu \mathrm{g} / \mathrm{ml}$ doxorubicin, (Doxo 1); $10 \mu \mathrm{g} / \mathrm{ml}$ doxorubicin, (Doxo 10); unloaded anionic group (A0); anionic group loaded with $1 \mu \mathrm{g} / \mathrm{ml}$ doxorubicin (A1); anionic group loaded with $10 \mu \mathrm{g} / \mathrm{ml}$ doxorubicin (A10); unloaded cationic group (C0); cationic group loaded with $1 \mu \mathrm{g} / \mathrm{ml}$ doxorubicin (C1); cationic loaded with $10 \mu \mathrm{g} / \mathrm{ml}$ doxorubicin (C10); unloaded neutral (N0); neutral group loaded with $1 \mu \mathrm{g} / \mathrm{ml}$ doxorubicin (N1); and neutral group loaded with $10 \mu \mathrm{g} / \mathrm{ml}$ doxorubicin (N10).

\section{Discussion}

This report was intended to evaluate the effects of anionic, cationic, and neutral liposomes containing doxorubicin on the cellular viability, the secretion of vascular endothelial growth factor and stem cell marker expression of three-dimensional stem cell spheroids. This study clearly showed that doxorubicin-loaded anionic liposomes produced the most sustained release profile and cationic liposome produced the highest uptake of the examined stem cell spheroids.

The fabrication of anionic, cationic, and neutral liposomes were done using traditional film-hydration methods (12). The release profile showed that anionic liposomes had the slowest release rate compared with cationic and neutral 

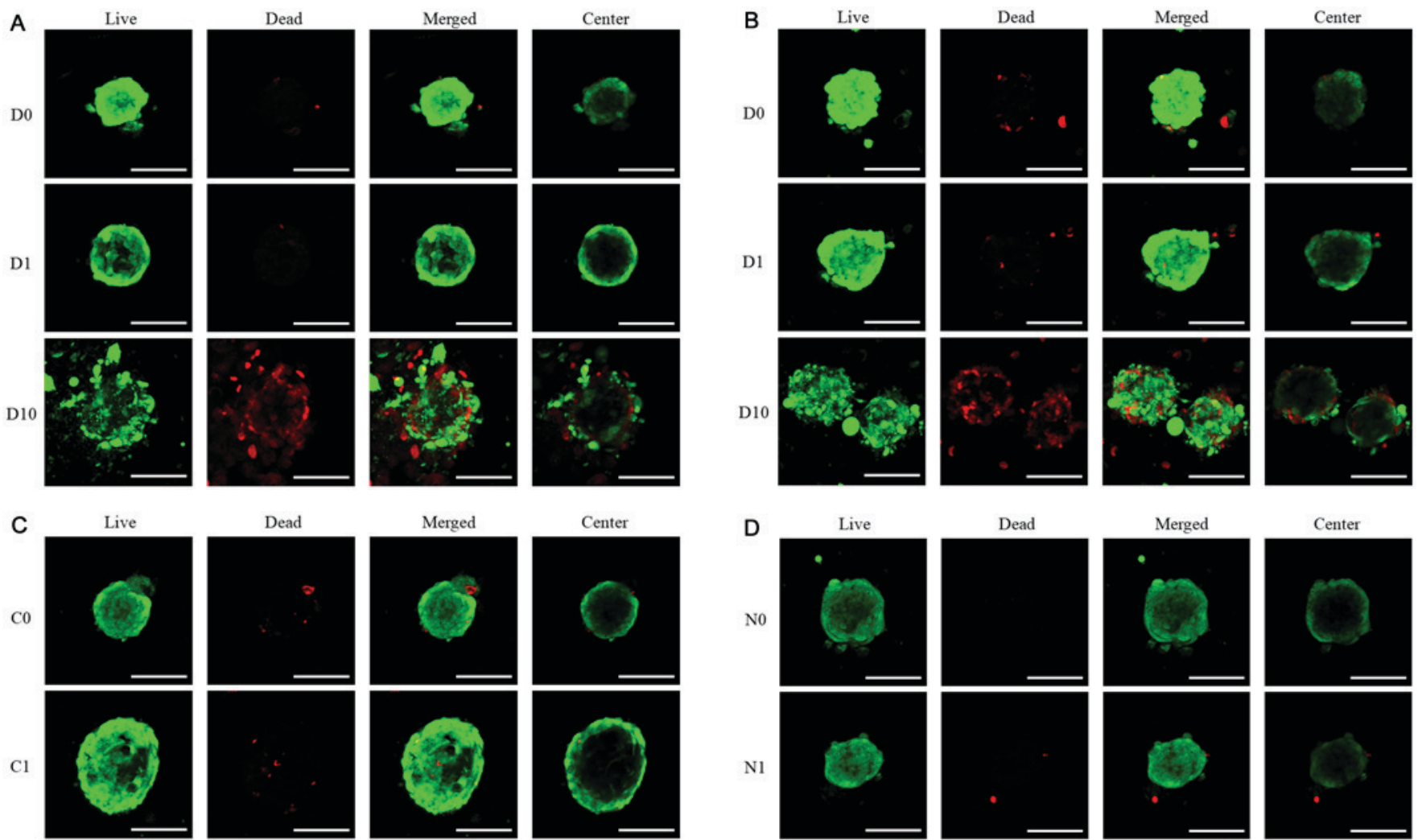

Merged
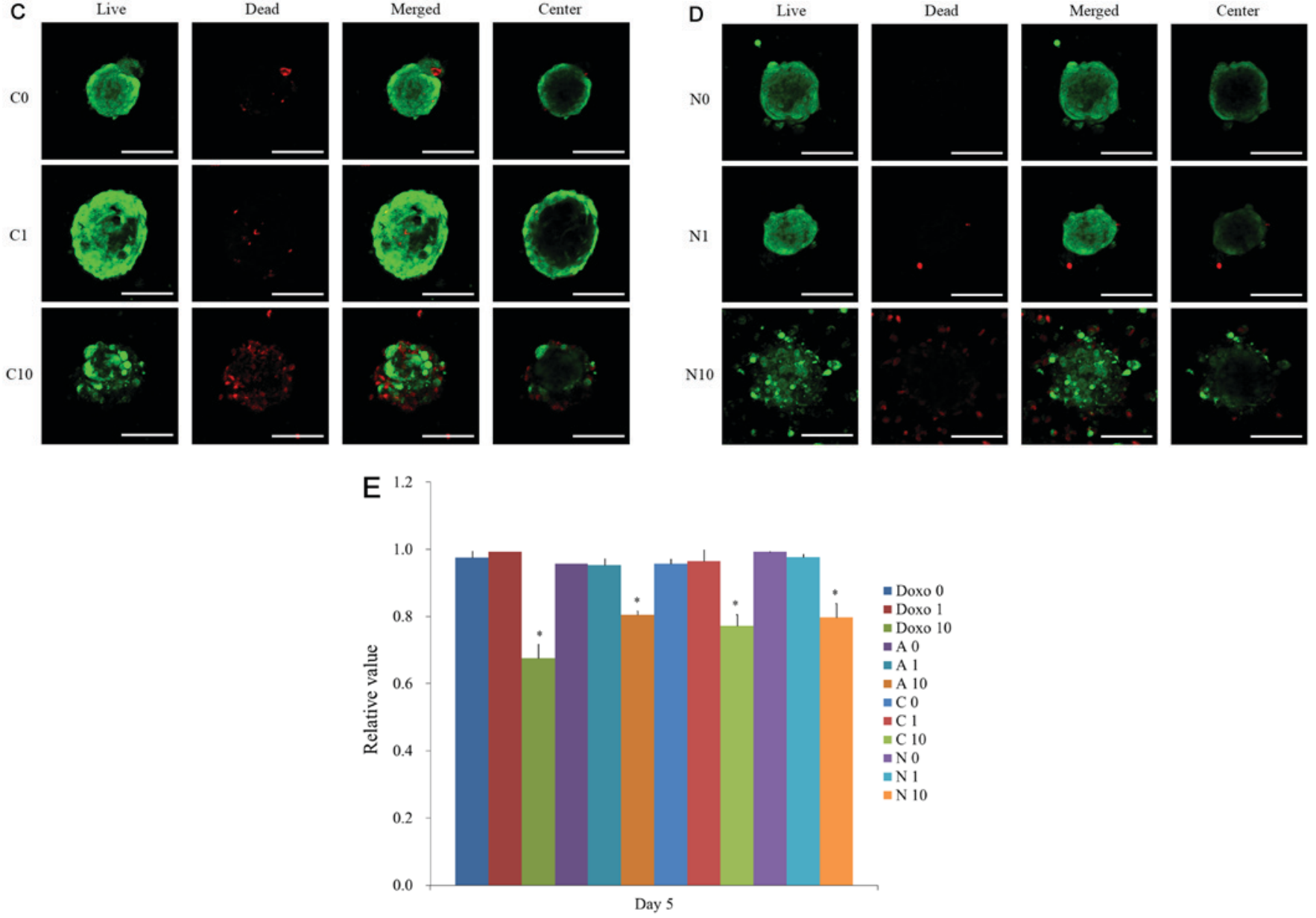

Figure 5. Qualitative results of cellular viability under a confocal microscope on day 5. Live images, dead images, merged images, and central images are provided. (A) Doxorubicin group; (B) anionic liposome; (C) cationic liposome; and (D) neutral liposome. Scale bar=100 $\mu \mathrm{m}$ (original magnification x100). (E) Quantitative results of cellular viability on day 5. ${ }^{*} \mathrm{P}<0.05$ vs. Doxo 0 group. The groups consisted of unloaded control group (Doxo 0); $1 \mu \mathrm{g} / \mathrm{ml}$ doxorubicin, (Doxo 1); $10 \mu \mathrm{g} / \mathrm{ml}$ doxorubicin, (Doxo 10); unloaded anionic group (A0); anionic group loaded with $1 \mu \mathrm{g} / \mathrm{ml}$ doxorubicin (A1); anionic group loaded with $10 \mu \mathrm{g} / \mathrm{ml}$ doxorubicin (A10); unloaded cationic group (C0); cationic group loaded with $1 \mu \mathrm{g} / \mathrm{ml}$ doxorubicin (C1); cationic loaded with $10 \mu \mathrm{g} / \mathrm{ml}$ doxorubicin (C10); unloaded neutral (N0; neutral group loaded with $1 \mu \mathrm{g} / \mathrm{ml}$ doxorubicin (N1); and neutral group loaded with $10 \mu \mathrm{g} / \mathrm{ml}$ doxorubicin (N10).

liposomes. This phenomenon possibly originated from the charge-charge interaction between the anionic charge of 1,2-dipalmitoyl-sn-glycero-3-phosphoserine and amine group of doxorubicin (1). The fluorescent properties of doxorubicin make it feasible to monitor the release profile of doxorubicin (13). In a previous report, doxorubicin was chemically conjugated to a terminal end group of poly (D,
L-lactic-co-glycolic acid) by an ester linkage, and the doxorubicin- poly (D, L-lactic-co-glycolic acid) conjugate was formulated and a sustained release of the doxorubicin was achieved at the injected site (14). If needed, these kinds of chemical linkage will result in slower release of doxorubicin compared to our liposomes. The viability of the stem cells were most significantly affected by cationic liposomes compared 


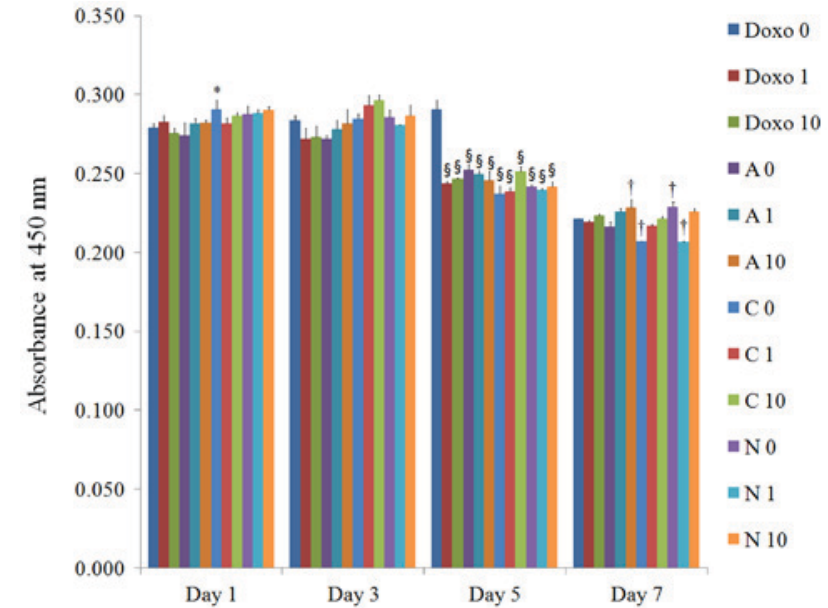

Figure 6. Cellular viability on days $1,3,5$ and 7 using CCK-8. ${ }^{*} \mathrm{P}<0.05$ vs. Doxo 0 group on day $1 ;{ }^{\circledR} \mathrm{P}<0.05$ vs. Doxo 0 group on day 5 ; ${ }^{\dagger} \mathrm{P}<0.05$ vs. Doxo 0 group on day 7. The groups consisted of unloaded control group (Doxo 0); $1 \mu \mathrm{g} / \mathrm{ml}$ doxorubicin, (Doxo 1); $10 \mu \mathrm{g} / \mathrm{ml}$ doxorubicin, (Doxo 10); unloaded anionic group (A0); anionic group loaded with $1 \mu \mathrm{g} / \mathrm{ml}$ doxorubicin (A1); anionic group loaded with $10 \mu \mathrm{g} / \mathrm{ml}$ doxorubicin (A10); unloaded cationic group (C0); cationic group loaded with $1 \mu \mathrm{g} / \mathrm{ml}$ doxorubicin $(\mathrm{C} 1)$; cationic loaded with $10 \mu \mathrm{g} / \mathrm{ml}$ doxorubicin (C10); unloaded neutral (N0); neutral group loaded with $1 \mu \mathrm{g} / \mathrm{ml}$ doxorubicin (N1); and neutral group loaded with $10 \mu \mathrm{g} / \mathrm{ml}$ doxorubicin (N10). CCK-8, Cell-Counting Kit-8. with anionic and neutral liposomes. It showed that the surface charge of the liposomes may affect their binding and uptake to the stem cells, similar to the cases of tumor cells (15). That application of stem cell spheroids should meticulously be performed to obtain optimal results for the individuals with anticancer therapy.

Previous studies showed that doxorubicin induces decreases of cell survival and differentiation (16). The morphology of higher concentrations of doxorubicin group seemed more dispersed and this may be due to a loss of cell-to-cell and cell-matrix interactions $(9,17)$. The cellular microenvironment is reported to affect maintenance of stemmenss (17), and the stem cell spheroids maintained the expression of stem cell marker during the experimental periods. However, the treatment of doxorubicin seemed to produce a reduced expression of stem cell markers.

Various methods can be used for the fabrication of three-dimensional tissue culture model (17). Hanging drop methods and rotary cell culture systems can be used to generate spheroids $(18,19)$. In this report, the silicon elastomer-based concave microwells were used for the fabrication of a three-dimensional system. Various materials can be used for the surface of microwells, including polyethylene
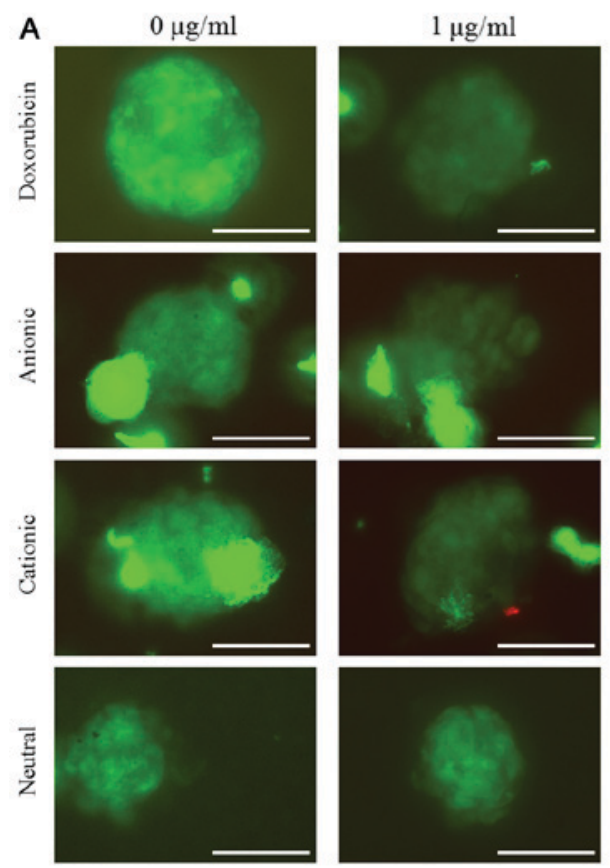
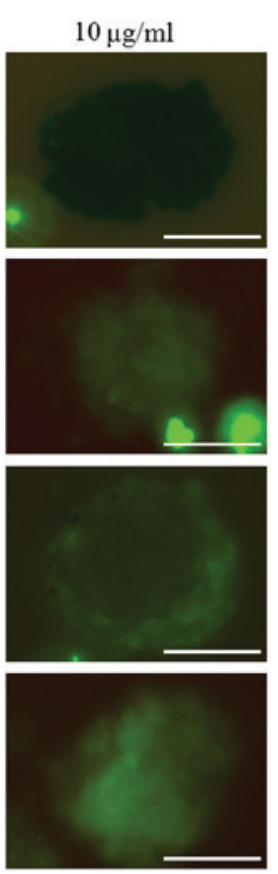
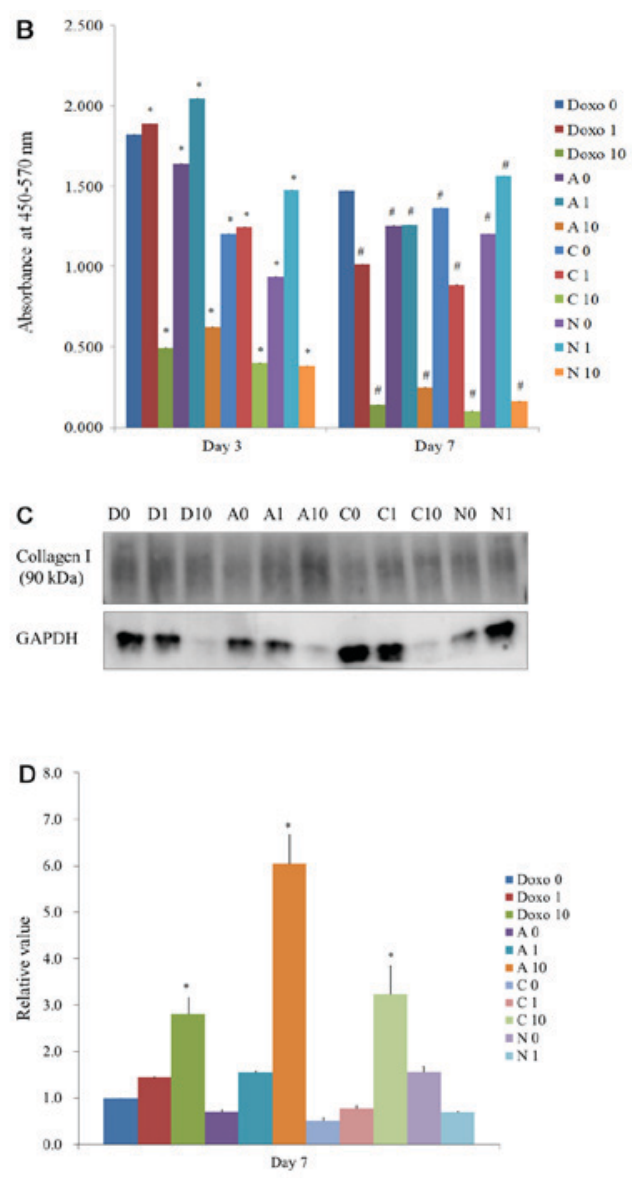

Figure 7. Expression stem cell marker, secretion of vascular endothelial growth factors and western blot analysis. (A) Maintenance of stemness was evaluated using immunocytochemical staining with NL493-conjugated SSEA-4 on day 7. The scale bar indicates $100 \mu \mathrm{m}$ (original magnification, x200). (B) Secretion of vascular endothelial growth factors from cell spheroids on days 3 and 5 . ${ }^{*} \mathrm{P}<0.05$ vs. Doxo 0 group on day $3 ;{ }^{\#} \mathrm{P}<0.05$ vs. Doxo 0 group on day 7 . (C) Western blot analysis to detect the collagen I protein expressions on day 7. (D) Quantitative results of cellular Western blot analysis on day 7. ${ }^{*} \mathrm{P}<0.05$ vs. Doxo 0 group. The groups consisted of unloaded control group (Doxo 0); $1 \mu \mathrm{g} / \mathrm{ml}$ doxorubicin, (Doxo 1); $10 \mu \mathrm{g} / \mathrm{ml}$ doxorubicin, (Doxo 10); unloaded anionic group (A0); anionic group loaded with $1 \mu \mathrm{g} / \mathrm{ml}$ doxorubicin (A1); anionic group loaded with $10 \mu \mathrm{g} / \mathrm{ml}$ doxorubicin (A10); unloaded cationic group (C0); cationic group loaded with $1 \mu \mathrm{g} / \mathrm{ml}$ doxorubicin (C1); cationic loaded with $10 \mu \mathrm{g} / \mathrm{ml}$ doxorubicin (C10); unloaded neutral (N0); neutral group loaded with $1 \mu \mathrm{g} / \mathrm{ml}$ doxorubicin (N1). 
glycol, polydimethylsiloxane, and polyurethane $(20,21)$. The morphology can be modified by the shape of the microwells (10), and the size of the spheroids can also be controlled by the number of applied cells (5). Three-dimensional cultures can be made with the aid of scaffolds including alginate (6). In this study, a scaffold-free culture system was used for the fabrication of spheroids and a higher number of cells can be applied for same amount of space (22).

The fabricated cell spheroids can be analyzed with various methods. A protein assay can be used for the measurements because the assay measures the protein content of the cells, making it an indirect method (23). Dye-exclusion tests, including the trypan blue test, can also be used based on the principle that live cells with intact membranes are not stained (24). The 3-(4,5-dimethylthiazol-2-yl)-2,5-diphenyltetrazolium bromide assay, which measures mitochondrial dehydrogenase activity of the tested cells, can be considered a more sensitive test (25). In this test, the qualitative analysis of cell viability was done with Live/Dead assay with confocal microscopy, which is based on the fluorescence of thin-sectioned images without complex fixation (26). A quantitative analysis was conducted with a CCK-8 assay (27). This assay does not require the solubilization process and the agent used is reported to be less toxic with a higher sensitivity $(28,29)$.

This study demonstrated that doxorubicin-loaded anionic liposomes produced the most sustained release profile, and cationic liposomes produced the highest uptake of the stem cell spheroids. Higher concentrations of doxorubicin-loaded liposomes affected cellular viability, the secretion of vascular endothelial growth factor and stem cell marker expression. These overall results showed that the formulation of liposomes influenced in different outcome in viability, the secretion of vascular endothelial growth factor and stem cell marker expression of three-dimensional stem cell spheroids.

\section{Acknowledgements}

The Catholic MASTER Cells supplied by Catholic Institute of Cell Therapy (CIC, Seoul, Korea) were derived from human bone marrow donated by healthy donors after informed consent.

\section{Funding}

This study was supported by Basic Science Research Program by the Ministry of Education (2016R1C1B3013951) through the NationalResearch Foundation of Korea and the financial support of the Catholic Medical Center Research Foundation made in the program year of 2016. This research was also supported by Basic Science Research Program through the National Research Foundation of Korea (NRF) funded by the Ministry of Science, Information and Communication Technology \& Future Planning (NRF-2017R1A1A1A05001307) and by Research Fund of Seoul St. Mary's Hospital, The Catholic University of Korea.

\section{Availability of data and materials}

All data generated or analyzed during this study are included in the published article.

\section{Authors' contributions}

HL, JS, CN, GY, HK and JP collaborated to design the study. HL, JS, CN, GY, HK and JP performed the experiments and data analysis. HL, JS, CN, GY, HK and JP collaborated to write the manuscript. All the authors reviewed the final manuscript.

\section{Ethics approval and consent to participate}

The Institutional Review Board of Seoul St. Mary's Hospital, College of Medicine, Catholic University of Korea (Seoul, Republic of Korea) approved the present study (KC17SESI0290 and KC11SISI0348) and informed consent from the study participants was obtained.

\section{Consent for publication}

Not applicable.

\section{Competing interests}

The authors declare that they have no competing interests.

\section{References}

1. Abraham SA, Waterhouse DN, Mayer LD, Cullis PR, Madden TD and Bally MB: The liposomal formulation of doxorubicin. Methods Enzymol 391: 71-97, 2005.

2. A Soliman N, Abd-Allah SH, Hussein S and Alaa Eldeen M Factors enhancing the migration and the homing of mesenchymal stem cells in experimentally induced cardiotoxicity in rats. IUBMB Life 69: 162-169, 2017

3. Csikos Z, Kerekes K, Fazekas E, Kun S and Borbely J: Biopolymer based nanosystem for doxorubicin targeted delivery. Am J Cancer Res 7: 715-726, 2017.

4. Fite BZ, Kheirolomoom A, Foiret JL, Seo JW, Mahakian LM, Ingham ES, Tam SM, Borowsky AD, Curry FE and Ferrara KW: Dynamic contrast enhanced MRI detects changes in vascular transport rate constants following treatment with thermally-sensitive liposomal doxorubicin. J Control Release 256: 203-213, 2017.

5. Lee SI, Yeo SI, Kim BB, Ko Y and Park JB: Formation of size-controllable spheroids using gingiva-derived stem cells and concave microwells: Morphology and viability tests. Biomed Rep 4: 97-101, 2016.

6. Wang WZ, Yao XD, Huang XJ, Li JQ and Xu H: Effects of TGF- $\beta 1$ and alginate on the differentiation of rabbit bone marrow-derived mesenchymal stem cells into a chondrocyte cell lineage. Exp Ther Med 10: 995-1002, 2015.

7. Li Y, Dal-Pra S, Mirotsou M, Jayawardena TM, Hodgkinson CP, Bursac N and Dzau VJ: Tissue-engineered 3-dimensional (3D) microenvironment enhances the direct reprogramming of fibroblasts into cardiomyocytes by microRNAs. Sci Rep 6: 38815, 2016.

8. Lo YP, Liu YS, Rimando MG, Ho JH, Lin KH and Lee OK: Three-dimensional spherical spatial boundary conditions differentially regulate osteogenic differentiation of mesenchymal stromal cells. Sci Rep 6: 21253, 2016.

9. Hsiao C, Tomai M, Glynn J and Palecek SP: Effects of 3D microwell culture on initial fate specification in human embryonic stem cells. AIChE J 60: 1225-1235, 2014.

10. Lee SI, Ko Y and Park JB: Evaluation of the maintenance of stemness, viability and differentiation potential of gingivaderived stem-cell spheroids. Exp Ther Med 13: 1757-1764, 2017.

11. Bhinge KN, Gupta V, Hosain SB, Satyanarayanajois SD, Meyer SA, Blaylock B, Zhang QJ and Liu YY: The opposite effects of doxorubicin on bone marrow stem cells versus breast cancer stem cells depend on glucosylceramide synthase. Int J Biochem Cell Biol 44: 1770-1778, 2012.

12. Lowery A, Onishko H, Hallahan DE and Han Z: Tumor-targeted delivery of liposome-encapsulated doxorubicin by use of a peptide that selectively binds to irradiated tumors. J Control Release 150: 117-124, 2011. 
13. Shah S, Chandra A, Kaur A, Sabnis N, Lacko A, Gryczynski Z, Fudala R and Gryczynski I: Fluorescence properties of doxorubicin in PBS buffer and PVA films. J Photochem Photobiol B 170: 65-69, 2017.

14. Yoo HS, Lee KH, Oh JE and Park TG: In vitro and in vivo anti-tumor activities of nanoparticles based on doxorubicin-PLGA conjugates. J Control Release 68: 419-431, 2000.

15. Lee S, Lee SY, Park S, Ryu JH, Na JH, Koo H, Lee KE, Jeon H, Kwon IC, Kim K and Jeong SY: In vivo NIRF imaging of tumor targetability of nanosized liposomes in tumor-bearing mice. Macromol Biosci 12: 849-856, 2012.

16. Rana T, Chakrabarti A, Freeman $M$ and Biswas $S$ : Doxorubicin-mediated bone loss in breast cancer bone metastases is driven by an interplay between oxidative stress and induction of TGF $\beta$. PLoS One 8: e78043, 2013.

17. Zhang S, Liu P, Chen L, Wang Y, Wang Z and Zhang B: The effects of spheroid formation of adipose-derived stem cells in a microgravity bioreactor on stemness properties and therapeutic potential. Biomaterials 41: 15-25, 2015.

18. Tang Y, Xu Y, Xiao Z, Zhao Y, Li J, Han S, Chen L, Dai B, Wang L, Chen B and Wang H: The combination of three-dimensional and rotary cell culture system promotes the proliferation and maintains the differentiation potential of rat BMSCs. Sci Rep 7: 192, 2017.

19. Ylostalo JH, Bazhanov N, Mohammadipoor A and Bartosh TJ: Production and administration of therapeutic mesenchymal stem/stromal cell (MSC) spheroids primed in 3-D cultures under Xeno-free conditions. J Vis Exp: Mar 18, 2017.

20. Mohr JC, de Pablo JJ and Palecek SP: 3-D microwell culture of human embryonic stem cells. Biomaterials 27: 6032-6042, 2006

21. Khademhosseini A, Ferreira L, Blumling J III, Yeh J, Karp JM, Fukuda J and Langer R: Co-culture of human embryonic stem cells with murine embryonic fibroblasts on microwell-patterned substrates. Biomaterials 27: 5968-5977, 2006.
22. Rogozhnikov D, O'Brien PJ, Elahipanah S and Yousaf MN: Scaffold free bio-orthogonal assembly of 3-dimensional cardiac tissue via cell surface engineering. Sci Rep 6: 39806, 2016.

23. Park JB, Zhang H, Lin CY, Chung CP, Byun Y, Park YS and Yang VC: Simvastatin maintains osteoblastic viability while promoting differentiation by partially regulating the expressions of estrogen receptors $\alpha$. J Surg Res 174: 278-283, 2012.

24. Park JB: Effects of 17- $\alpha$ ethynyl estradiol on proliferation, differentiation \& mineralization of osteoprecursor cells. Indian J Med Res 136: 466-470, 2012.

25. Park JB: Low dose of doxycyline promotes early differentiation of preosteoblasts by partially regulating the expression of estrogen receptors. J Surg Res 178: 737-742, 2012.

26. Barker LP, George KM, Falkow S and Small PL: Differential trafficking of live and dead Mycobacterium marinum organisms in macrophages. Infect Immun 65: 1497-1504, 1997.

27. Ha DH, Pathak S, Yong CS, Kim JO, Jeong JH and Park JB: Potential differentiation ability of gingiva originated human mesenchymal stem cell in the presence of tacrolimus. Sci Rep 6: 34910, 2016.

28. Almazin SM, Dziak R, Andreana S and Ciancio SG: The effect of doxycycline hyclate, chlorhexidine gluconate and minocycline hydrochloride on osteoblastic proliferation and differentiation in vitro. J Periodontol 80: 999-1005, 2009.

29. Jue SS, Lee WY, Kwon YD, Kim YR, Pae A and Lee B: The effects of enamel matrix derivative on the proliferation and differentiation of human mesenchymal stem cells. Clin Oral Implants Res 21: 741-746, 2010. International (CC BY-NC-ND 4.0) License. 